Haggie, S.J., Fermont, D.C. \& Wyllie, J.H. (1976) Treatment of duodenal ulcer with cimetidine. Lancet, $\mathrm{i}, 983$.

Harken, A.H., Gabel, R.A., Fenel, V. \& Moore, F.D. (1975). Hydrochloric acid in the correction of metabolic alkalosis. Archives of Surgery, 110, 819.

Hertz, P. \& Richardson, J.A. (1972) Arginine-induced hyperkalemia in renal failure patients. Archives of Internal Medicine, 130, 778.

KAsSIRER, J.P. (1974) Serious acid-base disorders. New England Journal of Medicine, 291, 773.

Kassirer, J.P., Berkman, P.M. \& LaWrenZ, D.R. (1965) The critical role of chloride in the correction of hypokalemia alkalosis in man. American Journal of Medicine, 38, 172.

Macdougall, B.R.D., Bailey, R.J. \& Williams, R. (1977) $\mathrm{H}_{2}$-receptor antagonists and antacids in the prevention of acute gastrointestinal haemorrhage in fulminant hepatic failure - two controlled trials. Lancet, i, 617.

Misiewicz, J.J. \& Burland, W.L. (1976) Cimetidine and ulcers. (Correspondence.) British Medical Journal, 2, 1445.
Pounder, R.E., Hunt, R.H., Stekelman, M., MiltonThompson, G.J. \& Misiewicz, J.J. (1976) Healing of gastric ulcer during treatment with cimetidine. Lancet, $\mathbf{i}$, 337.

RANDALl, H.T. (1976) Fluid, electrolyte and acid-base balance. Surgical Clinics of North America, 56, 1019.

SchWARTZ, W.B., VAN YPERSELE DE STRIHOU, C. \& KasSirer, J.P. (1968) Role of anions in metabolic alkalosis and potassium deficiency. New England Journal of Medicine, 279, 630.

Shavelle, H.S. \& Parke, R. (1975) Postoperative metabolic alkalosis and acute renal failure: rationale for the use of hydrochloric acid. Surgery, 78, 439.

Stage, J.G., Rune, S.J., Stadil, F. \& Worning, H. (1977) Treatment of Zollinger-Ellison patients with cimetidine. In: Cimetidine. Proceedings of the Second International Symposium, Royal College of Physicians (Ed. by W. L. Burland \& M. A. Simkins), p. 306. Excerpta Medica, Amsterdam and Oxford.

Williams, S.E. (1976) Hydrogen ion infusion for treating severe metabolic alkalosis. British Medical Journal, 1, 1189.

Postgraduate Medical Journal (February 1978) 54, 123-126.

\title{
Dermal gangrene. A rare complication of warfarin therapy
}

\author{
C. A. HARDisty \\ B.Sc., M.R.C.P. \\ Academic Division of Medicine, Clinical Sciences Centre, Northern General Hospital, Sheffield S5 7AU
}

\begin{abstract}
Summary
Two cases of dermal gangrene following warfarin therapy are described and a review of the literature is given.
\end{abstract}

\section{Introduction}

Two cases of dermal gangrene have been seen following warfarin therapy. In both cases, the loading doses of warfarin were administered in the presence of impaired hepatic function and proved to be inappropriately high.

\section{Case no. 1}

A 62-year-old woman was admitted four weeks following a routine cholecystectomy with a history suggestive of multiple pulmonary emboli. Her haemoglobin was $10.2 \mathrm{~g} / \mathrm{dl}$ with an iron deficiency picture, hepatic enzymes were elevated - SGOT 66 i.u./l (normal 5-17 i.u./l), SGPT 63 i.u./l (normal 5-17 i.u./l), $\gamma$ GT 42 i.u./l (normal 0-16 i.u./l), bilirubin and alkaline phosphatase were within normal limits. She was given intravenous heparin 10000 units 6-hourly for $48 \mathrm{hr}$ and $30 \mathrm{mg}$ warfarin orally.
Two days later her prothrombin time was $44 \mathrm{sec}$ (control $11 \mathrm{sec)}$ so that no further warfarin was given. The next day she complained of pain in the right hypochondrium. On examination, a striking raised erythematous skin lesion measuring 8 by $4 \mathrm{~cm}$ with sharply demarcated edges was found to be extremely tender. A provisional diagnosis of intracutaneous haemorrhage due to overdosage with anticoagulant was made. The prothrombin time was $64 \mathrm{sec}$ (control $13 \mathrm{sec}$ ) and $10 \mathrm{mg}$ of vitamin $\mathrm{K}_{1}$ were given intravenously. Over the next week the affected area blistered and then became necrotic; finally, being covered by a black eschar (Fig. 1). Her haemoglobin fell to $8.5 \mathrm{~g} / \mathrm{dl}$ and it was eight days before the prothrombin time fell to within the therapeutic range. At this time small doses of warfarin were reintroduced without complications and the prothrombin time was satisfactory. The lesion took four months to heal, leaving only a small scar.

\section{Case no. 2}

A 49-year-old man was admitted with bacterial endocarditis on the aortic valve with severe cardiac 


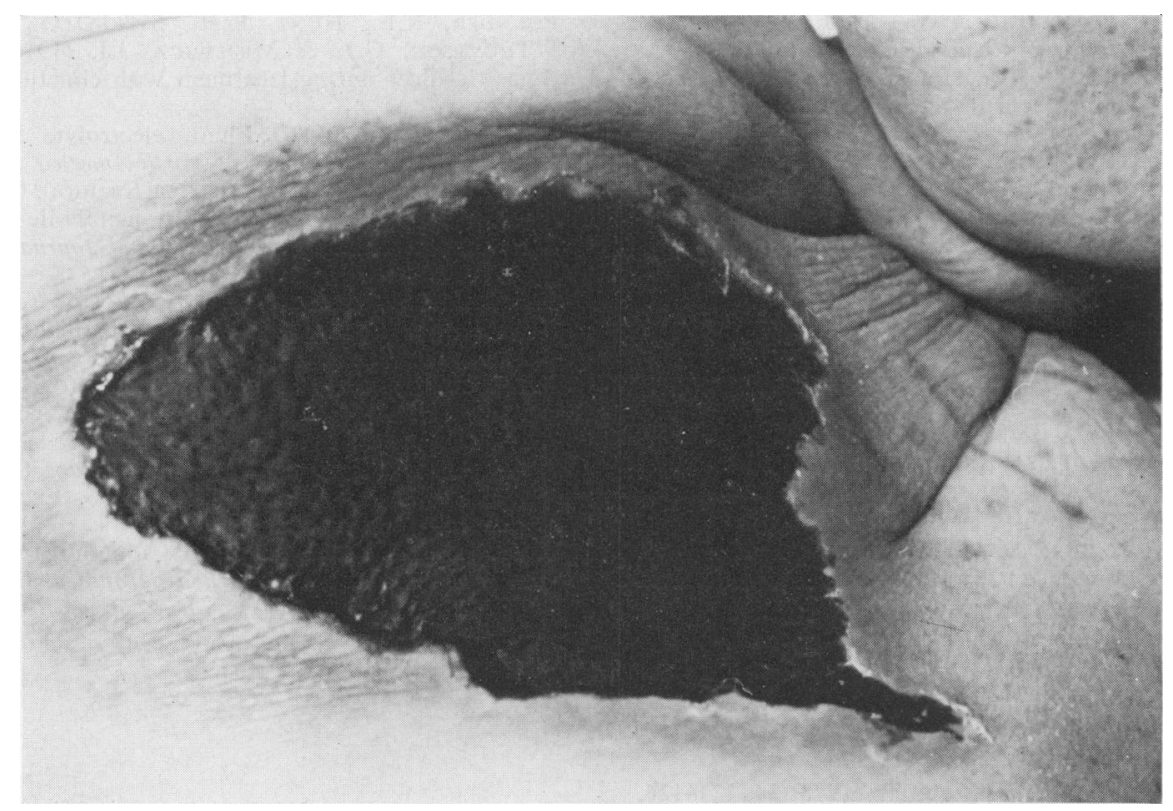

FIG. 1. Appearance of lesion in right hypochondrium at three weeks.

failure and an emergency aortic valve replacement was undertaken. Before surgery his prothrombin time was slightly elevated at $16 \mathrm{sec}$ (control $12 \mathrm{sec}$ ) and hepatic enzymes were elevated - SGOT 44 i.u./1 (normal 5-17 i.u./l), SGPT 55 i.u./1 (normal 5-17 i.u./l). The serum bilirubin was normal $-16 \mu \mathrm{mol} / \mathrm{l}$ (normal 5-16 $\mu \mathrm{mol} / \mathrm{l}$ ). Three days following surgery his haemoglobin was $11.9 \mathrm{~g} / \mathrm{dl}$ and he was given a 30-mg loading dose of warfarin according to the routine practice of the unit. Four days later, large bruises were noted over his left chest, right hypochondrium and right arm. His prothrombin time was $74 \mathrm{sec}$ (control $12 \mathrm{sec}$ ) and a diagnosis of intracutaneous haemorrhage was made. Vitamin $K_{1}$ was given but the prothrombin time took ten days to fall within the therapeutic range. As in Case no. 1, the lesions became gangrenous and a black eschar formed (Fig. 2); skin grafting was required. His haemoglobin fell to $10.4 \mathrm{~g} / \mathrm{dl}$. Warfarin was reintroduced but his anticoagulation was always difficult to control. After repeated questioning he finally confessed to being a heavy drinker.

\section{Discussion}

Dermal gangrene was first recognized as a complication of oral anticoagulation using dicoumarol (Verhagen, 1954) but it can be caused by any of the coumarin derivatives. More cases are seen in women than men but the incidence is estimated to be less than 1 in a 1000. The lesions typically occur three nine days after the start of therapy and may be single or multiple, commonly involving areas wh abundant subcutaneous fat such as buttocks, abdomen, thighs and breasts. Lesions of the foe have never been described. Usually the patient complains of pain and an elevated, tender, erythematoms patch is seen over the affected area. Petechial haemorrhages may be seen and the lesion may stọp at this point. More commonly, it becomes discoloured and, within a day, becomes necrotic wh haemorrhagic blisters. The necrosis involves whole skin and penetrates the subcutaneous fint. Over the next week a black, leathery eschar forms and healing may take months. Skin grafting may required for extensive scarring, and amputation of breasts and genitalia has been described (Kipen, 1961; Vaughan et al., 1969).

The actual cause of the lesion remains unknown. Histological studies have been made but are difficult to interpret as they have been performed followitg the onset of necrosis (Nudelman and Kempses, 1966; Davis, Wiley and Faulconer, 1972). Leucocyte infiltration, venous thrombosis and perivascutar haemorrhages involving the capillaries and venu两es are described. On the basis of these findings it fas been hypothesized that the coumarin derivatives act directly on the dermovascular loop (Nalbandianet al., 1965). Simple haemorrhage due to overdosage 


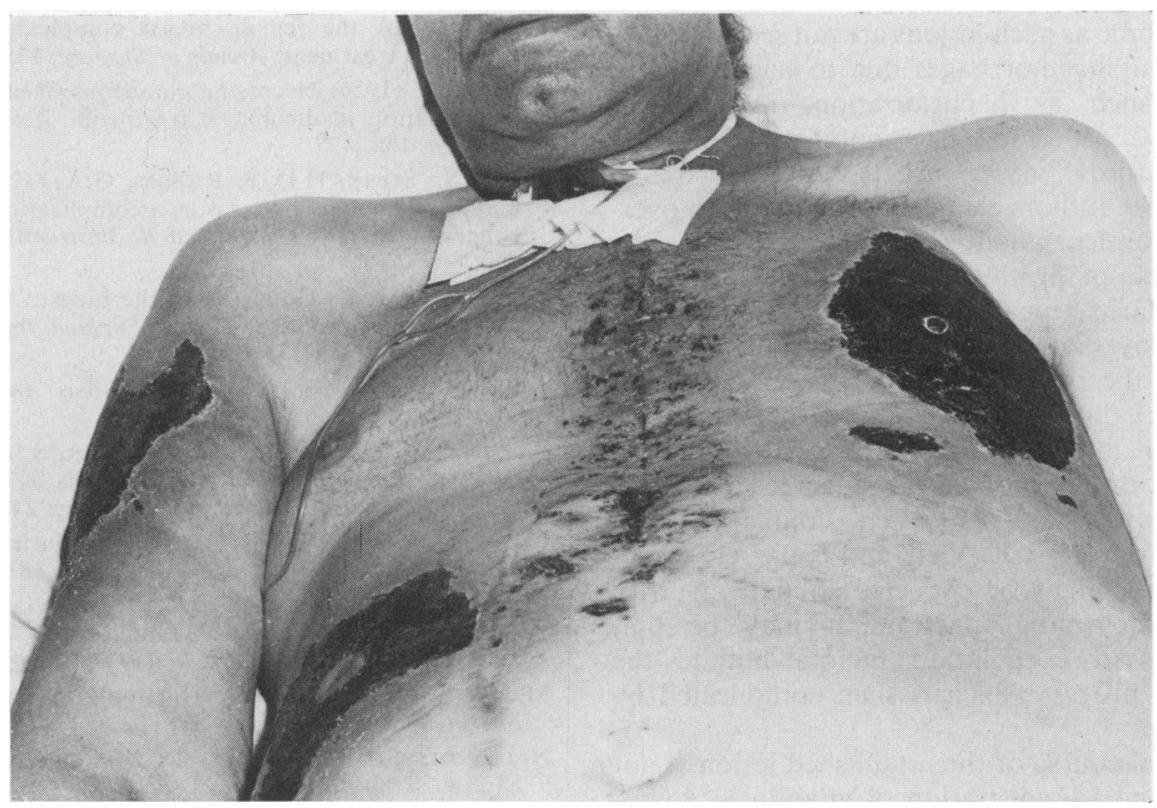

Fig. 2. Appearance of multiple lesions in case 2 at three weeks.

TABLE 1. Cases of warfarin-induced dermal gangrene

\begin{tabular}{|c|c|c|c|c|c|}
\hline \multicolumn{2}{|c|}{$\begin{array}{l}\text { Sex and } \\
\text { age (year) }\end{array}$} & \multirow{2}{*}{$\begin{array}{c}\begin{array}{c}\text { Site of lesion and number of days } \\
\text { from start of therapy }\end{array} \\
\text { Anterior surface right thigh, day } 3\end{array}$} & \multirow{2}{*}{$\begin{array}{c}\begin{array}{c}\text { Warfarin } \\
\text { dosage } \\
\text { initial (Total) } \\
(\mathrm{mg})\end{array} \\
25(40)\end{array}$} & \multirow{2}{*}{$\begin{array}{c}\begin{array}{c}\text { Prothrombin } \\
\text { time in sec. }\end{array} \\
42(15)^{*}\end{array}$} & \multirow[b]{2}{*}{ Korbitz et al., 1969} \\
\hline $\mathbf{F}$ & 16 & & & & \\
\hline $\mathbf{M}$ & 36 & Penis, day 3 & $50(125)$ & $33(12 \cdot 5)$ & Vaughan et al., 1969 \\
\hline $\mathbf{F}$ & 48 & Right breast, day 3 & $50(60)$ & $65(12)$ & $\begin{array}{l}\text { Romanucci, Jakovic and } \\
\text { Smedberg, } 1974\end{array}$ \\
\hline $\mathbf{F}$ & 75 & Right breast, day 5 & 65 total & $48(15)$ & Martin and Philipps (1970) \\
\hline $\mathbf{F}$ & 61 & Left breast, day 4 & $30(47 \cdot 5)$ & $32 \cdot 5(14)$ & Davis, Wiley and Faulconer, \\
\hline $\mathbf{F}$ & 73 & Right breast, day 4 & $40(45)$ & $38(12)$ & 1972 \\
\hline $\mathbf{F}$ & 64 & $\begin{array}{l}\text { Right forearm, hand and thigh, left } \\
\text { forearm and hip, day } 3\end{array}$ & $15(35)$ & $45 \cdot 8-$ & Lacy and Goodin, 1975 \\
\hline $\mathbf{F}$ & 59 & Left breast, day 3 & $10(25)$ & $15 \%$ normal & Shnider and D'Souza, 1976 \\
\hline $\mathbf{F}$ & 52 & Left breast, day 6 & $50(60)$ & $28 \cdot 4(11 \cdot 7)$ & \multirow{2}{*}{\} $\begin{array}{l}\text { Kahn, Stern and Rhodes, } \\
1971\end{array}$} \\
\hline $\mathbf{F}$ & 69 & Left breast and buttock, day 4 & $30(85)$ & $60(13)$ & \\
\hline $\mathbf{F}$ & 23 & Left thigh, day 5 & $15(42 \cdot 5)$ & $35(12 \cdot 5)$ & \multirow{3}{*}{ Nalbandian et al., 1965} \\
\hline $\mathbf{F}$ & 39 & Right ankle and foot, day 3 & $30(50)$ & $41(12 \cdot 5)$ & \\
\hline $\mathbf{M}$ & 50 & Right flank and hypochondrium, day 5 & $40(65)$ & $33(12 \cdot 4)$ & \\
\hline $\mathbf{F}$ & 72 & Right breast and buttock, day 5 & $50(-)$ & $46-$ & $\begin{array}{l}\text { Nudelman and Kempson, } \\
1966\end{array}$ \\
\hline $\mathbf{M}$ & 56 & Lateral aspect of both thighs, day 4 & $15(42 \cdot 5)$ & $30(11)$ & Chua et al., 1973 \\
\hline $\mathbf{F}$ & 53 & Right breast, day 3 & $25(45)$ & - & \multirow{2}{*}{ Mason, 1970} \\
\hline $\mathbf{F}$ & 78 & Left breast, day 3 & $15(35)$ & - & \\
\hline
\end{tabular}

* Figures in parentheses indicate control. 
with anticoagulant is discounted as the primary cause of the syndrome as such lesions are not seen in extensive cutaneous haemorrhages due to haemorrhagic conditions such as heparinization, avitaminosis $\mathrm{K}$, vitamin $\mathrm{C}$ deficiency, haemophilia and fibrinogenopenia (Jordal, 1956; Koch-Weser, 1968). In addition, most authors claim that there was no overdosage with anticoagulant in their cases. However, a critical review of prothrombin times seen in cases due to warfarin reveals that most were probably overtreated by present-day criteria (Table 1). Certainly, both the present cases had excessively high prothrombin times and significant haemorrhage occurred. An interesting observation is the sudden change in prothrombin times seen in affected patients compared with controls when coumarin anticoagulants are restarted (Viets and Gebauer, 1968). Such changes might be expected in patients with compromised hepatic function. It may be that sudden falls in coagulation factors initiate the pathological process which is then complicated by haemorrhage.

The clinical course of the established lesion is not affected by the administration of vitamin $\mathrm{K}$, hypothermia, vasodilators, sympathetic nerve block and vitamin C. Amputation, resection, debridement and skin grafting are sometimes necessary. As in the present two cases, warfarin can usually be reintroduced with no further complications but recurrence of lesions has been described (Jordal, 1956).

\section{Acknowledgments}

I am grateful to Mr D. Taylor, Consultant Cardiothoracic Surgeon, Northern General Hospital, Sheffield, and Professor D. S. Munro for permission to report details on patients admitted under their care.

\section{References}

Chua, F.S., Chiscano, A.D., Wukasch, D.C., Chapman, D.W. \& Cooley, D.A. (1973) Dermal gangrene. An unpredictable complication of coumarin therapy. Journal of Thoracic and Cardiovascular Surgery, 65, 238.
Davis, C.E., Wiley, W.B. \& FAulconer, R.J. (19君) Necrosis of the female breast complicating oral anicoagulant treatment. Annals of Surgery, 175, 647.

JORDAL, R. (1956) Necrosing cutaneous haemorrhages așa complication in dicumarol treatment. Acta medica scchdinavica, 154, 477.

KahN, S., Stern, H.D. \& Rhodes, G.A. (1971) Cutaneōis and subcutaneous necrosis as a complication of couma $\overline{\overline{m i n}}$ congener therapy. Plastic and Reconstructive Surgery, 160.

KIPEN, C.S. (1961) Gangrene of the breast. A complicationn of anticoagulant therapy. New England Journal of Medicine, 265, 638.

KOCH-WeSER, J. (1968) Coumarin necrosis. Annals of Intermal Medicine, 68, 1365.

Korbitz, B.C., Ramirez, G., Mackman, S. \& Davis, Hơ़् (1969) Coumarin-induced skin necrosis in a sixteen-ye然old girl. American Journal of Cardiology, 24, 420.

LACY, J.P. \& GoodIN, R.R. (1975) Warfarin-induced necrosis of skin. Annals of Internal Medicine, 82, 381.

Martin, B.F. \& Phillips, J.D. (1970) Gangrene of the female breast with anticoagulant therapy. Report of two cases. American Journal of Clinical Pathology, 53, 622. N

MASON, J.R. (1970) Haemorrhage-induced breast gangreße. British Journal of Surgery, 57, 700.

Nalbandian, R.M., Mader, I.J., Barrett, J.L., Peare两, J.F. \& RUPP, E.C. (1965) Petechiae, ecchymoses a用 necrosis of skin induced by coumarin congeners. Journafgf the American Medical Association, 192, 107.

Nudelman, H.L. \& Kempson, R.L. (1966) Necrosis of the breast: a rare complication of anticoagulant thepapd. American Journal of Surgery, 111, 728.

Romanucci, D., Jakovic, L.G. \& SmedberG, K. (\$9 Anticoagulants and haemorrhage - breast necrosis: report. Angiology, 25, 612.

SHNider, M. \& D'SouzA, C.R. (1976) Cutaneous gangrerg: a rare complication of coumarin therapy. Canadion Journal of Surgery, 19, 64.

Vaughan, E.D., Moore, R.A., Warren, H., Moler, D.श. \& GillenWATER, J.Y. (1969) Skin necrosis of genitalia a $\overrightarrow{f d}$ warfarin therapy. Journal of the American Medical Assoctgtion, 210, 2282.

VERHAGEN, H. (1954) Local haemorrhage and necrosis of skin and underlying tissues, during anticoagulant therapy with dicumarol or dicumacyl. Acta medica scandinavisa, 148, 453.

Viets, C.H. \& Gebauer, D. (1968) Coumarin necrosis. German Medical Monthly, 13, 23. 